\title{
TEJIENDO UN DOBLE MANTO PURPÚREO: TRAMAS FEMENINAS EN ILÍADA*
}

\author{
Elsa Rodríguez Cidre ${ }^{* *}$
}

\begin{abstract}
Resumen: El mundo de lo textil es parte integral de casi toda cultura humana y cumple en cada una de ellas distintas funciones sociales. En el ámbito de la épica griega la referencia a lo textil es constante. El poeta suele demorarse en las descripciones de vestuario o en las referencias a labores textiles que delata un conocimiento directo. En la Grecia antigua este mundo tiene una ligazón íntima con las mujeres porque constituye un trabajo casi exclusivamente femenino y porque, en tanto suplemento del cuerpo, ejerce un papel clave en la construcción de la propia identidad femenina. Los elementos textiles (como otros objetos del ốkos) sirven asimismo de medio de comunicación no verbal para las mujeres, lo que permite ampliar el escaso margen de acción y de expresión de unos personajes que, prescriptivamente, tienen una agencia limitada en la épica. Es nuestro objetivo en el presente artículo analizar los tejidos de Helena en el canto III y de Andrómaca en el XXII para establecer comparaciones y determinar similitudes y diferencias.
\end{abstract}

Palabras claves: tejido; trama; Helena; Andrómaca; Ilíada.

\section{WEAVINGADOUBLE PURPLE CLOAK: FEMALE FABRICSAT ILIAD}

Abstract: The world of textiles is an integral part of almost every human culture and fulfills different social functions. In Greek epic the reference to textiles is continuous. The poet often lingers in costume descriptions or in references to textile work that reveal direct knowledge. In ancient Greece, this world has an intimate bond with women because it constitutes an almost exclusively feminine work and because, as a supplement to the body, it plays a key role in the construction of the feminine identity. Textile elements (like other objects in the oikos) also serve as a means of non-verbal communication for women, which allows for a broadening of the limited range of

\footnotetext{
* Recebido em: 29/08/2020 e aprovado em: 30/10/2020.

** Professora doutora adjunta da Área de Grego da Universidade de Buenos Aires e do Mestrado em Estudos Clássicos da mesma instituição (de cuja Comissão é membro). Investigadora adjunta do Conicet. E-mail: elsarodriguez022@gmail.com. ORCID: https://orcid.org/0000-0003-2197-3066.
} 
action and expression of characters who, prescriptively, have limited agency in the epic. The main objective of this article is to analyze the weavings of Helen at book 3 and Andromache at book 22 of Homer's Iliad to establish comparisons and determine similarities and differences.

Keywords: weaving; fabric; Helen; Andromache; Iliad.

El mundo de lo textil (incluyendo bajo esta denominación las vestimentas, sus accesorios y las distintas labores que hacen a su confección) es parte integral de casi toda cultura humana y cumple en cada una de ellas distintas funciones sociales, con especial eficacia en lo que concierne a las construcciones identitarias (BENDER JØRGENSEN, 2007, p. 1; BARBER, 2007, p. 1).

En el ámbito de la épica griega (en Ilíada, en particular, que es el centro de este artículo), la referencia a lo textil es constante y ello a partir de la constatación de una obviedad: todos aparecen vestidos, los mortales pero también los dioses y hasta las almas en pena, como la del mísero Patroclo, cuando en XXIII (vv. 65-67) se mencionan los vestidos, cil $\mu \alpha \tau \alpha$, que cubrían su cuerpo. El poeta suele demorarse en las descripciones de vestuario o en las referencias a labores textiles, a veces con un nivel de detalle que delata un conocimiento directo, tal como ocurre a menudo en los símiles que emplea. En un mundo donde lo textil es omnipresente y de tanta relevancia, lógicamente toda referencia a la ausencia de vestimenta, total o parcial, está cargada de significatividad, en general en relación con el deshonor o el riesgo de caer en él. Un ejemplo manifiesto lo da el maltrato de Odiseo para con Tersites cuando amenaza con echarlo de la asamblea

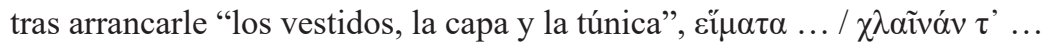
$\chi 1 \tau \tilde{\omega} v \alpha$, que cubren sus vergüenzas (II, vv. 261-262). Asimismo, la desnudez deshonra a los cadáveres de los derrotados como en las estructuras formularias que el poeta emplea respecto del cuerpo de Patroclo, desnudo por cuanto fue despojado de su armadura por su vencedor (XVII, vv. 121-122), o del cadáver de Héctor, desnudo junto a las corvas naves, lejos de sus padres y a merced de perros y movedizos gusanos, como dice Andrómaca en XXII (vv. 508-509). Por último, señalemos que esa carga de deshonor también puede ser voluntaria como en la semidesnudez en el marco de la súplica, ritual codificado que incluye un rebajamiento estratégico que busca un efecto persuasivo. Tal es el caso del descubrimiento del pecho de Hécuba en XXII (v. 80), motivo este de la mostración de senos que el registro trágico explotará luego con fruición (RODRÍGUEZ CIDRE, 2011). 
Ahora bien, en la Grecia antigua, como sabemos, el mundo textil tiene una ligazón íntima con las mujeres, por varios factores. En primer lugar, constituye un trabajo casi exclusivamente femenino que compete tanto a las mujeres de la élite (sobre las que veremos luego) como a las del pueblo de las que poco y nada se habla en Ilíada (uno de los escasos ejemplos lo da Homero cuando menciona en XII - vv.433-435 - a una pobre viuda con una vida miserable hilando lana para otros - BARBER, 2007, p. 1). Una forma que tiene el texto de hacer patente el carácter femenino de las tareas textiles viene dado cuando sitúa al mismo personaje en calidad de princesa en el presente y en condición de esclava en el futuro, evidenciando que una u otra condición conllevará labores textiles. Se trata de Andrómaca a quien Héctor ordena en VI (vv. 490-492): “mas yendo a palacio ocúpate de tus labores, no solo del telar sino también de la rueca y ordena a las sirvientas

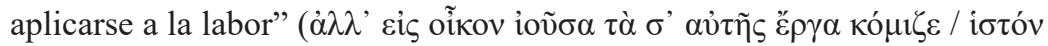

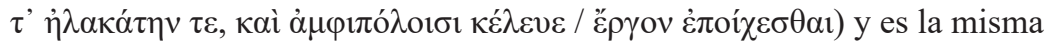
Andrómaca a la que su marido imagina cautiva en VI (v. 456) diciéndole:

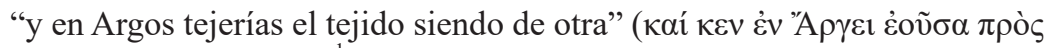

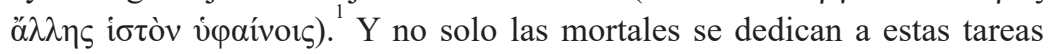
pues las diosas también lo hacen como es el caso de Atenea de cuyo peplo se nos dice en las estructuras formularias del poema que es de muchos colo-

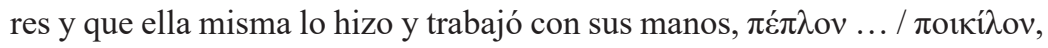

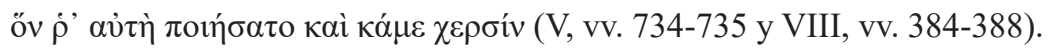

Por otro lado, si bien lo textil, en tanto suplemento del cuerpo, manifiesta e incluso determina tipos de identidad social muy distintos (de clase, de pertenencia étnica, de grupo etáreo, de género, etc. - LEE, 2012, p. 180), se puede plantear, en virtud de la injerencia femenina en todo lo relativo a lo textil en la sociedad antigua, que ejerce un papel clave en la construcción de la propia identidad femenina. Como plantea Lee (2012, p. 180), la evidencia arqueológica y literaria resalta la fuerte asociación ideológica entre las mujeres y la actividad textil que está en la base de la construcción identitaria femenina y confirma su doble rol de productoras, para el marido, de niños y de tejidos al interior del ốkos.

Por último, los elementos vinculados a lo textil (como otros objetos del oîkos) sirven asimismo de medio de comunicación no verbal para las mujeres, ${ }^{2}$ lo que les permite ampliar el escaso margen de acción y de expresión de unos personajes que, prescriptivamente, tienen una agencia limitada en la épica. Un ejemplo de ello hallamos en las cuestiones estudiadas por Ca- 
nevaro (2019) en torno de la capacidad de las mujeres épicas de fundar y preservar la memoria a través del tejido. De acuerdo con este trabajo sobre memorialización (CANEVARO, 2019, p. 53-54 y 57-58), se puede constatar cómo los objetos vinculados a lo femenino (en un marco doméstico donde la multiplicidad de estos realza la falta de sujetos agentes a la vez que la prolongada ausencia de hombres) encajan con el tono narrativo adoptado en respuesta a la escasa capacidad de incidencia de las mujeres.

Estas consideraciones marcan el contexto para el punto que queremos abordar aquí: la capacidad que la narración épica puede conferir a los personajes femeninos de configurar la trama narrativa a través de las referencias a lo textil. Para ello, debemos antes tener presente dos cuestiones. En primer lugar, que el propio entramado narrativo es pensado en Grecia como un tejido del poeta: el recurso a metáforas textiles para describir el trabajo de composición poética revela una clara autoconciencia por parte de los creadores antiguos, quienes se ven a sí mismos como artesanos entrenados en la técnica del tejido ${ }^{3}$ (WAGNER-HASEL, 2020 [2000]). En segundo lugar, que la vida de los personajes (como la de los mortales en términos generales) es pensada también como un tejido, esta vez a cargo de las Moiras o el destino. La metáfora del hilo de la vida cristaliza en unas estructuras recurrentes que asocian el inicio del tejido con el momento del parto: así en términos similares, por un lado, en XX (v. 128) Hera refiere a Eneas, quien debe evitar enfrentarse a Aquiles, que sufrirá más tarde lo que el destino tejió con el lino para él al nacer, cuando su madre lo dio a

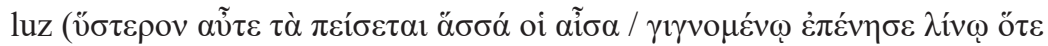
$\mu \mathrm{v} \tau \varepsilon \dot{\kappa} \varepsilon \varepsilon \eta \dot{\tau} \tau \rho)$, por otro, en XXIV (vv. 209-210), Hécuba le dice a Príamo sobre Héctor que eso es lo que "la poderosa Moira tejió con el lino para él

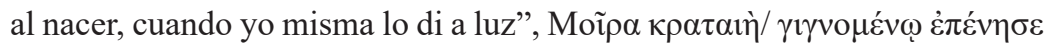

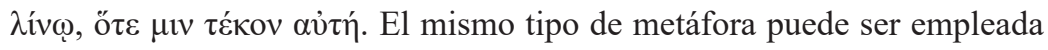
también en términos más generales teniendo a los dioses como agentes, como en la afirmación de Aquiles en XXIV (vv. 525-526) acerca de que

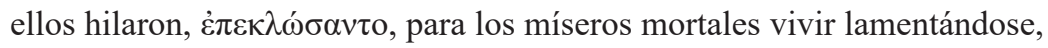
o en la queja de Odiseo en XIV (vv. 85-87) porque Zeus destinó devanar, $\tau 0 \lambda v \pi \varepsilon v ́ \varepsilon i v$, desde la juventud hasta la vejez dolorosas guerras, hasta que nos consumamos uno a uno. Señalemos, por último, como hace notar Wagner-Hasel (2020 [2000], p. 237) que esta referencia textil se refuerza en VIII (vv. 69-72) con la imagen del pesaje de las almas a la manera de los trabajadores de la lana. 
En cuanto a la idea de tramas femeninas que hemos incorporado en nuestro título, podemos pensar en distintas modalidades de intervención. Por un lado, una más directa, más explícita, en la que el personaje femenino urde una trama a la manera del ardid. No nos detendremos en esta cuestión, en gran medida por su escasa presencia en el texto de Ilíada, lo que se corresponde con la limitada agencia de estos personajes épicos, situación opuesta a lo que ocurre en el registro trágico. A diferencia de la Penélope de Odisea que encarna una forma acabada de ardid femenino ligado al tejido (y destejido, claro), en Ilíada nos tendríamos que trasladar al plano divino y remitirnos al episodio del canto 14 cuando Hera recurre a distintos elementos textiles como el vestido y el velo para seducir a Zeus y lograr que el dios esté ausente por un tiempo en la contienda. Ambos ardides, el de la esposa de Odiseo y el de la esposa de Zeus, aun diversos en su contenido, son homólogos en cuanto al éxito en demorar situaciones que ambas desean prolongar.

Pero, por otro lado, podemos plantear una forma de intervención más sutil, donde las tramas textiles femeninas se enhebran con la trama narrativa de manera más implícita aunque quizá de cariz más estructural. Se trata de dos casos de prefiguración de la trama narrativa que analizaremos en dos escenas en espejo que se relatan en los cantos III y XXII, protagonizados por Helena y Andrómaca respectivamente.

\section{Helena esparce numerosas hazañas de ambos bandos}

En el primer escenario, Iris, bajo la apariencia de Laódice, va a buscar a Helena a su aposento y el poeta nos narra que:

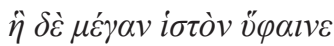

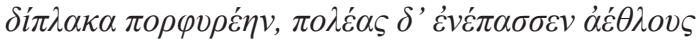

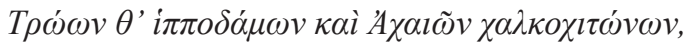

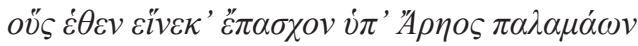

ella tejía un gran tejido, un doble manto purpúreo, y esparcía numerosas hazañas de troyanos, domadores de caballos, y de aqueos, de broncíneas túnicas, quienes por causa suya padecían bajo las manos de Ares. (III, vv. 125-128) 
Estos versos, que dan entrada a la obra al personaje sobre el que se monta toda la historia en cuestión, especifican que el "gran tejido" consiste en "un doble manto purpúreo". Detengámonos en primer lugar en el púrpura. ${ }^{5}$ Por un lado, se trata de un color que denota lujo y jerarquía. ${ }^{6}$ Así, a lo largo de la obra, el púrpura colorea el manto de importantes personajes como Agamenón en canto VIII (v. 221) o Néstor en X (v. 133), aunque también puede aplicarse a elementos textiles que no son prendas de vestir como los tapetes que Aquiles ofrece a Fénix, Áyax y Odiseo en canto IX (v. 200) o las sábanas que el Pelida ordena colocar en los catres donde descansarán Príamo y su heraldo en XXIV (v. 645). Pero, por otro lado, el púrpura ostenta también una valencia tanática. Así aparece calificando a

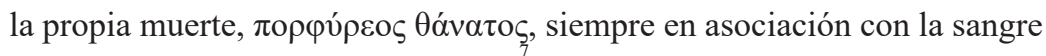
derramada de los caídos en combate. También serán púrpuras dos prendas que giran en torno de la muerte de Héctor. Por un lado, el cinturón relucien-

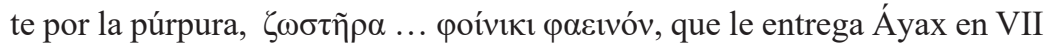
(v. 305) como contradón a la espada que recibe del troyano. El elemento tanático en este caso se activa cuando Aquiles sujeta el cuerpo de Héctor al carro por este cinturón para arrastrarlo alrededor de la ciudad. Tam-

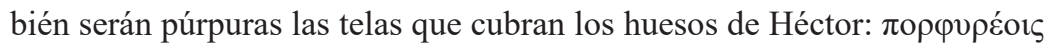

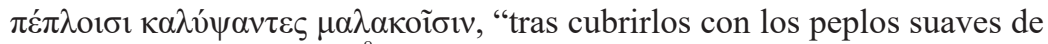
púrpura" (XXIV, v. 796).

Por otra parte, en el verso 126 se dice que Helena esparce colores en el

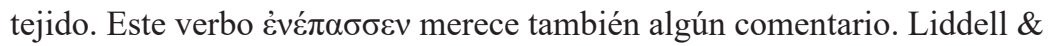
Scott \& Jones (1968) da para દ̇ $\mu \pi \alpha ́ \sigma \sigma \omega$ como primera acepción "rociar/esparcir" y luego señala que en Homero solo es metafórico significando "tejer ricos estampados en un tejido"; sus citas son precisamente los dos mantos que aquí nos ocupan. Leaf (1900) sostiene que este verbo señala que el arte del tejido se hallaba altamente desarrollado en esos días e imagina que la técnica apuntaría a insertar hilos de colores a mano a la manera del tapiz de Bayeux del s. XI donde las damas de Normandía bordaban las victorias del duque. Ahora bien, ¿cuáles serían los ricos estampados en este caso? El texto dice que se trata de $\pi$ o $\lambda \dot{\varepsilon} \alpha \varsigma$... $\alpha \dot{\varepsilon} \theta \lambda \mathrm{ou \varsigma}$, "numerosas hazañas".

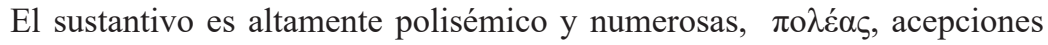
podrían ser también tejidas en esta tela. Rodríguez Adrados (1989) da para $\tilde{\alpha} \theta \lambda \circ \varsigma$, seis acepciones y todas podrían aplicarse a la escena del tejido de Helena. El primer valor es el de "hazaña o proeza concebida como esfuerzo penoso" y aquí cita solamente nuestro ejemplo; luego da el significado 
de "sufrimiento, dolor, fatiga" (consecuencias lógicas de la primera acepción); en tercer lugar el de "hazaña infausta, acción calamitosa" (la guerra se aproxima a los diez años de duración); el siguiente remite a la "prueba puesta por Penélope a sus pretendientes" (recordemos que los griegos están luchando en Troya por la promesa dada justamente a Tindáreo cuando fueron pretendientes de Helena de que todos acudirían si le pasaba algo a ella); un quinto significado apunta a "concurso, competición, juegos" (que nos reenvía, por un lado, al concurso de Paris cuando elige a Afrodita y con ella a Helena y, por otro, a los juegos fúnebres que se desarrollarán respecto de Patroclo, donde, por cierto, no hay prendas textiles entre los premios) y por último, un sentido más genérico de "combate, lucha". Todos estos significados entran en este gran manto que el texto también califica de doble.

Para Leaf (1900) $\delta i ́ \pi \lambda \alpha \xi$ describe un manto lo suficientemente grande para ser usado doble y para Seymour (1891) es doble porque permite dar dos vueltas al cuerpo. Ahora bien, este carácter doble del tejido, además de denotar sus dimensiones, parece involucrar los dos "hilos" de esta guerra, griegos y troyanos. Los genitivos del verso 127 replican en la decoración la

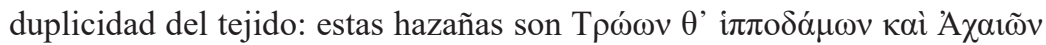
$\chi \alpha \lambda \kappa o \chi \imath \tau \omega ́ v \omega v$, "de troyanos, domadores de caballos, y de aqueos, de broncíneas túnicas". El epíteto de los troyanos, domadores de caballos, es uno de los principales epítetos de Héctor y con esta función es la última palabra de la obra. El epíteto de los aqueos nos trae otra prenda, la túnica, aunque en este caso parece anularse su valencia textil ya que el bronce remite a la armadura de guerra. Estos dos hilos principales del tejido, troyanos y aqueos, padecen bajo las manos, las palmas, de Ares, el dios de la guerra. Kirk (1985) imagina los àś $\theta \lambda$ ov de Helena como 'combates' formales de pares de guerreros dispuestos a lo largo de los bordes de la tela. Pero recordemos que la escena del tejido es contemporánea de la preparación del duelo individual entre Menelao y Paris que pronto va a iniciarse y que motiva la aproximación de Iris (esta simultaneidad representa para Kirk un patético símbolo de la omnipresencia de la guerra).

Ahora bien, Helena (como el poeta se ocupa de decir en el verso 128,

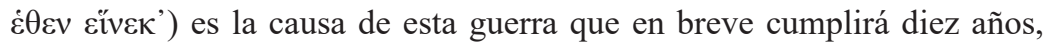
con lo cual ella no solo está volcando sobre la base de un púrpura tanático la imagen potente del enfrentamiento entre dos bandos de guerreros, sino que replica en el paño un conflicto entre hombres que la tienen en su origen y en su centro, aún si ella no aparece representada en la imagen. Si bien 
como señala Roisman (2006, p. 10) esta autorreferencialidad podría ser vista como un signo de arrogancia, piedad de sí y ensimismamiento, lo cierto es que el foco del tejido de Helena no está en ella sino en los héroes que sufren. En un sentido, este hecho crea una distancia entre Helena y el combate que la tienen como objeto de disputa y la ubica, en cambio, más en posición de artista que inmortaliza las acciones de los hombres a la manera de Homero. En este rol, deja de ser un mero objeto de intercambio y de posesión masculinos para transformarse en una creadora en su propio derecho. En esta línea de análisis, Canevaro (2019, p. 55) sostiene que Helena conmemora la historia de la guerra de Troya al tejerla (a la inversa de Penélope que conmemora a su esposo retrasando la finalización de su tejido). El carácter de poietés que parece asumir Helena en esta escena se refuerza con la repetición de una estructura formularia que evidencia el paralelismo entre el decorado del manto y lo que está sucediendo extramuros: la mujer más hermosa del mundo teje las hazañas "de troyanos, domadores de caballos, y de aqueos, de broncíneas túnicas", Т $\rho \omega ́ \omega v \theta$ '

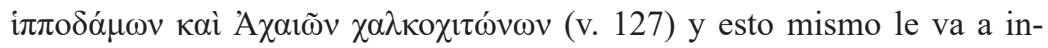

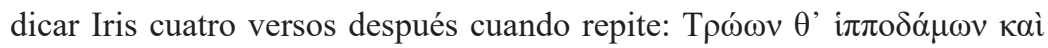

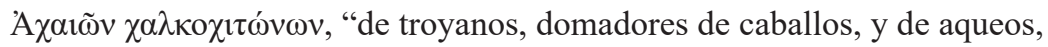
de broncíneas túnicas". Es decir, desde el éndon más recóndito Helena recrea sobre la tela lo que está ocurriendo en el éxo. Es cierto que se podría objetar que esta guerra está ya en el noveno año y que la imagen del tejido podría no ser más que un tópos pero lo cierto es que Helena está representando en la tela lo que está ocurriendo en ese preciso momento ante el duelo entre Menelao y Paris. Esta situación singular ha recibido muchas interpretaciones. Por un lado, para Canevaro (2019, p. 66-67), el orden y la repetición podrían indicar el status semidivino de Helena y en ese caso, su conocimiento privilegiado provendría de algo más que una experiencia empírica: Helena estaría tejiendo lo que aún no ha visto. Kennedy (1986, p. 9) remarca el hecho de que en el tejido la acción esté interrumpida no solo por el hecho de que ella lo deja para hacer lo que se le pide sino porque esta representación puede solo sugerir, no retratar la acción. Interrupción que también adelanta lo que sucederá con el duelo entre sus dos esposos. Iriarte \& González González (2008, p. 64) concluyen que "independientemente del valor que se le conceda a ese trabajo del telar, ya sea una metáfora de la labor del poeta, ya algo más, el objeto mismo de su canto, lo cierto es que Helena no deja en ningún caso de cumplir su función como "voluntad 
de Zeus" a la manera de Pandora. Otra lectura posible es la que planteaba Elena Huber en sus clases en la Universidad de Buenos Aires por la cual el tejido a manos de Helena implicaba una introducción subrepticia de los griegos en la ciudad asediada prefigurando el desarrollo de la trama mítica. De hecho, podemos agregar, que los griegos ingresan así al éndon más recóndito al que un enemigo podría acceder, con las consecuencias funestas esperables. La segunda entrada simbólica, decía Huber, se daba en el episodio de la teikhoskopía, la escena inmediatamente sucesiva a la del telar, cuando a pedido de Príamo Helena va nombrando a los principales héroes aqueos, vale decir que una invasión discursiva de los griegos a través de la boca de Helena vienen a replicar la invasión plástica que acaba de producirse a través de sus manos. Bergren (2008, p. 47) refuerza el paralelismo entre estas dos escenas sucesivas y, de hecho, analiza la teikhoskopía como un nuevo tapiz (KENNEDY, 1986, p. 6-8).

Todas estas consideraciones permiten graficar aquello que antes mencionáramos acerca de la actividad textil como un medio de comunicación no verbal de las mujeres. Ello se hace más evidente cuando rescatamos, con Roisman (2006, p. 10-11), el carácter silencioso de la escena de Helena ante el telar (quien emite discurso es Iris y no la espartana) al mismo tiempo que recordamos otra rememoración de la guerra, planteada por Iriarte \& González González, (2008, p. 49): estas autoras comparan a Helena con Aquiles ya que ambos personajes cantan las hazañas de los héroes y comparten esta función con el poeta. Pero recordemos que en el caso de Aquiles tal rememoración es discursiva: cuando la embajada lo visita para convencerlo de que retorne al combate y abandone su cólera contra Agamenón en el canto IX, Aquiles está cantando la gloria de los guerreros acompañado con la lira.

\section{Andrómaca esparce multicolores adornos y va más allá}

Andrómaca teje también un doble manto purpúreo, y, de hecho, se trata de las únicas dos menciones en el texto. Lo hace en el canto XXII, el tercero antes del final de la obra, ubicación en espejo a la del canto III al inicio. También aquí hay una relación significativa con los sucesos bélicos que ocurren extramuros pero el sentido de esa relación difiere en gran medida de lo que se cifra en el episodio de Helena, lo cual se vincula también con las diferencias en la configuración del propio paño: 


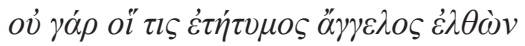

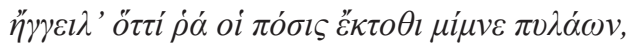

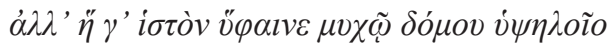

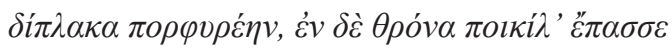

pues ningún verdadero mensajero, tras llegar, le anunció que su esposo permanecía alli fuera de las puertas, sino que ella tejía un tejido en lo más recóndito de (la) alta morada, un doble manto purpúreo y esparcía multicolores adornos. (XXII, vv. 438-441)

En efecto, un cambio radica en las imágenes tejidas: ya no son las haza-

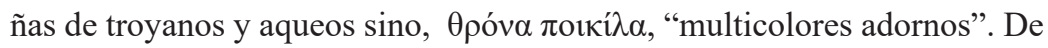
Jong (2012) nota que, si bien la etimología de $\theta \rho o ́ v \alpha$ es oscura, ya en la Antigüedad podía significar "flores" o simplemente "decoración". Liddell \& Scott \& Jones (1968) traduce "flores" para esta cita pero Leaf siguiendo a Helbig sugiere que el término puede ser tomado en un sentido amplio como "adorno" u "ornamento" ya que los estampados vegetales no se encuentran en las representaciones más antiguas de los vestidos con figuras y que seguramente la ornamentación debía ser geométrica. Lee (2012, p. 181) nos recuerda, además, que ninguna vestimenta completa del período arcaico o incluso clásico ha sido recobrada arqueológicamente. Segal (1971, p. 401), tomando la valencia floral del término, interpreta que su tejido representa símbolos de la vida y la esperanza que los dioses le niegan a Andrómaca: para esta mujer, las escenas de guerra no son reducibles al arte puesto que son terriblemente cercanas. También sostiene que Homero tiene otra razón para individualizar el tejido con los vívidos detalles del verso 441: no solo refleja la felicidad doméstica de la normal vida de esposa; también muestra una de las virtudes de Andrómaca, su obediencia marital en el momento en el que ese aspecto de su vida está agotado (recordemos que las últimas palabras de Héctor a ella conforman una orden a la vuelta al telar y a la rueca - VI, vv. 491-492). Sean elementos de la naturaleza (como flores o plantas) o adornos geométricos, lo cierto es que hay un gran contraste no solo con el tejido de Helena sino también con la realidad que la está rodeando, como si la base púrpura prevaleciera sobre esta ornamentación.

En efecto, su marido ya está afuera muerto, y no solo no apreciará ese tejido que ella está confeccionando en lo más recóndito de su morada, sino que tampoco hará uso del baño caliente que le está preparando ni vestirá las 
prendas dispuestas para él en el tálamo. Los adornos del manto son además

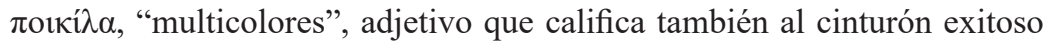
de Hera en el ardid del sueño de XIV (v. 215) y a dos peplos de Atenea, el dedicado por las mujeres troyanas (III, vv. 286 y ss.) y el que la misma diosa hizo con sus propias manos (V, vv. 734-735 y VIII, vv. 385-386). ${ }^{10}$ No obstante, la base sobre la que se despliega esa multiplicidad de colores es púrpura, elemento tanático que ella ya enuncia en sus primeras palabras del canto 6 cuando a un esposo vivo y combatiente en pleno vigor le hablaba como si ya estuviera muerto.

Richardson (2000[1993]) señala otro paralelo en estas dos escenas: ambas mujeres abandonan sus tejidos para ir a la muralla acompañadas de dos sirvientas y usando sus velos (III, vv. 141-145; XXII, vv. 460-463 y XXII, vv. 468-472). En el caso de la espartana, para ser, como vimos, el personaje principal en la teikhoskopia; en el caso de Andrómaca, para dar lugar a unas expresiones de dolor que renuevan en el éxo una peculiar relación entre ella y los objetos textiles. Aquí querríamos detenernos en dos situaciones nuevas respecto de lo analizado en el canto III. La primera, en relación directa con un objeto del tejer: en el verso 448 el poeta nos dice: $\tau \tilde{\eta} \varsigma \delta^{\prime} \dot{\varepsilon} \lambda \varepsilon \lambda \dot{i} \chi \theta \eta$

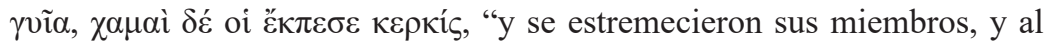
suelo se le cayó la lanzadera". El término aquí es кєркí, que traducimos por "lanzadera" y conforma la barra por la cual pasa el hilo de la trama. Ella porta consigo al éxo un elemento típico del éndon que se le cae cuando oye llantos y gemidos provenientes de la torre. Canevaro $(2019$, p. 58) señala que si el tejer en la épica simboliza la estabilidad y la continuidad, el hecho de que Andrómaca deje caer la lanzadera significa el inminente trastorno del ámbito doméstico (PANTELIA, 1993, p. 496). En segundo lugar, una vez producido el anagnorismós de la muerte de su marido y de la situación de tremenda crueldad que está experimentando su cadáver, se desmaya y cuando vuelve en sí procederá a desprenderse de sus accesorios textiles con un nivel de detalle por parte del poeta sin precedentes:

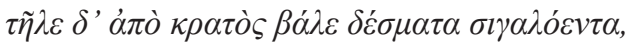

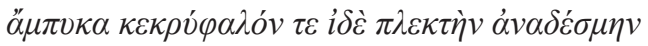

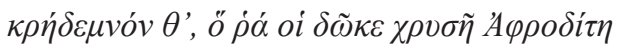

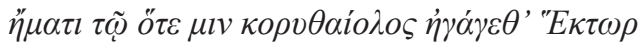

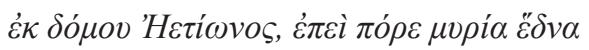


lejos de la cabeza arrojó los brillantes lazos, la diadema, la redecilla, la trenzada cinta y el velo que le dió la áurea Afrodita en el día en el que Héctor, de tremolante yelmo, la condujo desde la casa de Eetión, después que le dio una incontable dote. (XXII, vv. 468-472)

Andrómaca va desprendiéndose de cinco accesorios de vestuario que remiten todos al momento inaugural de su vida conyugal. La contraposición aquí entre las imágenes masculina y femenina en lo que hace al tocado no podría ser mayor. Mientras que Héctor luce un yelmo tremolante,

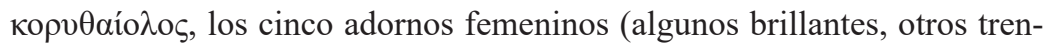
zados) están en función de sujetar o velar su cabeza: el vocablo que inicia la enumeración, $\delta \varepsilon ́ \sigma \mu \alpha \tau \alpha$, significa en su primera acepción precisamente "atadura". Por lo tanto, en la escena del canto XXII, Andrómaca va desatando y sacando los elementos que remitían a su ceremonia nupcial: estos gestos ligados a objetos textiles representan de forma no verbal el cambio de status que la mujer acaba de experimentar. De gyné, esposa, ha devenido khére, viuda, y sabe que, en breve, perderá también su condición de mujer libre: nada de la dorada Afrodita le servirá en su futuro. Dentro del conjunto de elementos que adornaban su cabeza, hay uno en el que querríamos

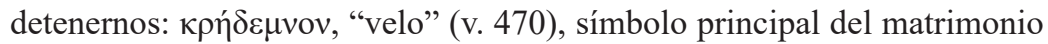
desde el momento en que la novia se vela para la ceremonia de bodas y luego da lugar a la $\alpha \dot{v} \alpha \kappa \alpha \lambda v \pi \tau \eta ́ \rho ı \alpha$ o desvelamiento en los esponsales cuando la novia se lo quitaba. Este vocablo también refiere al velo que usó Hera en XIV (v. 184) en el ya mencionado ardid que despliega para engañar a Zeus y lograr, por un rato, claro, su voluntad (situación antitética desde todo punto de vista con las circunstancias de Andrómaca). Canevaro (2019, 5p. 9), relaciona el episodio de Andrómaca con las palabras de Aquiles a Patroclo en XVI (v. 100) donde expresa su deseo de desatar con su compañero

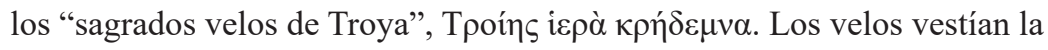
cabeza de Andrómaca y todavía visten las torres de Troya lo cual, en palabras de la autora, forja una conexión fuerte entre la mujer y la ciudad y más específicamente en lo que hace a la caída de ambas.

Desprendida de sus adornos, Andrómaca podrá empezar parcialmente con el registro discursivo del lamento fúnebre que completará con otro nivel de formalidad en el último canto de la obra. El texto se encarga de nombrar la cuantiosa dote de su matrimonio, lo que para Canevaro (2019, p. 59) recuerda el valor de Andrómaca cuando entró en etapa de circula- 
ción al abandonar el solar paterno. Ella reingresa ahora con la viudez en una nueva etapa de circulación pero la que se avizora en el horizonte es de otro tipo, ya que no estará entre las mujeres libres sino que pasará a ser

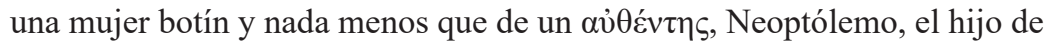
Aquiles, asesino de su esposo, cuyo cadáver está ultrajando en esos precisos momentos al arrastrarlo en círculos. ${ }^{13}$ Segal (1971, p. 37) nos hace percibir que al detener el lamento de Andrómaca hasta el v. 476, situación lograda por la descripción textil, Homero cumple dos propósitos específicos: primero, otorga a su dolor una especial prominencia (que el canto VI ya había justificado); segundo, evita una anticipación de una escena trenódica similar en el XXIV reservando para el final del poema el efecto más estilizado, más ritualizado y de ahí, más solemne. Aquí, en el XXII la agonía de la pérdida tiene todavía sus aristas más crudas. Nos acercamos tanto como podemos al shock y al horror del evento de la guerra. En este contexto, hay un paralelismo con Hécuba cuando también se desprende de

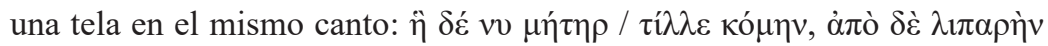

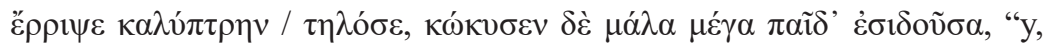
por otro, la madre en ese momento se arrancaba la cabellera y arrojó (de sí) el brillante velo lejos y lloró muy mucho tras ver a su hijo" (XXII, v. 405-407). En un episodio más reducido Hécuba se desprende del velo (con cambio de lexema) y comienza el lenguaje gestual del lamento fúnebre que también cerrará con otra formalidad en el canto XXIV.

Andrómaca es la gran anunciadora de lo que viene, una especie de Casandra en función de sus presentimientos y temores. Ya en el canto VI, como hemos mencionado, se dirige a Héctor como si ya hubiese muerto (algo que no ocurre ni con Hécuba ni con Helena). En el VI y en el XXII contempla el negro futuro para ella y Astianacte. En cuanto a su hijo, también recurre a objetos textiles para graficar su desamparo, imaginándolo

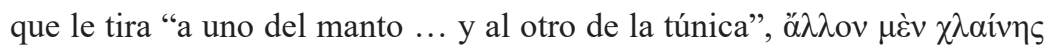
..., $\alpha \lambda \lambda \lambda \circ \vee \delta \grave{\varepsilon} \chi \imath \tau \tilde{\omega} \vee \circ($ XXII, v. 493).

Quedan finalmente, los últimos versos de este canto XXII donde Andrómaca vuelve a poner de relieve elementos textiles:

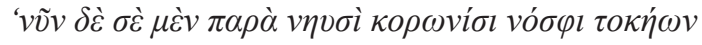

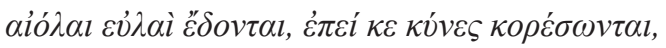

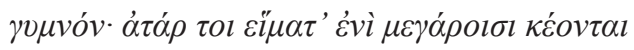




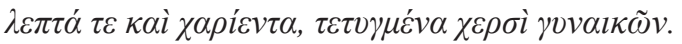

$\dot{\alpha} \lambda \lambda \lambda^{\prime} \eta \ddot{\tau o l} \tau \dot{\alpha} \delta \varepsilon \pi \alpha \dot{\alpha} \tau \alpha \kappa \alpha \tau \alpha \varphi \lambda \dot{\varepsilon} \xi \omega \pi \nu \rho \grave{\varepsilon} \kappa \eta \lambda \dot{\varepsilon} \omega$,

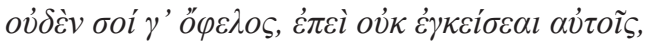

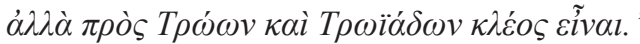

“...Y ahora a tí, por un lado, junto a las curvas naves lejos de tus padres los movedizos gusanos te comerán después de que los perros estén hastiados, desnudo. Pero yacen para ti vestiduras en palacio finas y también hermosas, producidas por las manos de las mujeres. Pero, en verdad, quemaré todas estas con ardiente fuego; para ti, ninguna utilidad porque no te las pondrás, sino que (ellas) son gloria para troyanos y troyanas (por ti).” (XXII, v. 508-514)

Vemos que Andrómaca contrapone la situación de desnudez humillante del cadáver de Héctor en el éxo extramuros con el lujoso e inútil vestuario que ha quedado en el éndon doméstico y su decisión al respecto es prenderle fuego. En esta pira, ella quemaría las finas y hermosas vestiduras de su marido, que pasarían a conformar una especie de efigie mortuoria que simbolice el cuerpo de Héctor, una suerte de cenotafio textil.

Las prendas de Héctor son explícitamente reenviadas al ámbito de acción femenina del éndon en el verso 511, donde se aclara que son "pro-

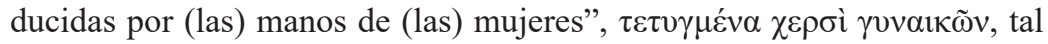
como en el verso 440 la misma Andrómaca aparecía tejiendo el manto ya analizado. En palabras de Segal (1971, p. 38), este incendio por Andrómaca de las ropas de Héctor destruye también una de las partes de su vida pasada, uno de los principales atributos de su rol como álokhos. Siguiendo esta línea (o podríamos decir, este hilo) Canevaro (2019, p. 59-60) remarca que la intención de destruir sus prendas se halla en total contraste con la estabilidad doméstica que se creía asegurada cuando tejía el manto en cuestión. Ahora bien, al tejer una vestidura y preparar un baño, Andrómaca está en el XXII anunciando los ritos funerarios que deberían aparecer en torno del cadáver de Héctor en el XXIV. Estas prendas están simbolizando dos ideales, el de la seguridad doméstica en vida, y el de un entierro apropiado en la muerte; el contraste aquí no sería entre vivo y muerto sino entre desnudo en la muerte y decorosamente cubierto y en este punto del relato Héctor está siendo privado de ambos ideales. 
Dijimos que Andrómaca es una gran anunciadora de la trama y en este caso vuelve a cumplir su rol. Las prendas que Héctor no usará ni siquiera en su lecho mortuorio constituirán la pira que suplante el funeral, en principio vedado, ante la ausencia del cadáver. Pero notemos que esta pira simbólica inauguraría una tríada de hogueras. La segunda se efectuará con la presencia efectiva del cadáver de Héctor con ritual fúnebre previo y absolutamente pautado en los días que Aquiles dispensó para Príamo. Cabe señalar que las prendas que viste el cadáver son las que el Pelida ordena a las mujeres que utilicen, deduciéndolas del cuantioso rescate que Príamo había llevado para intercambiar por el cuerpo de su hijo. Estas prendas, pues, salieron de Troya, y Aquiles decide que vuelvan a la pólis cubriendo el cuerpo desnudo de Héctor. Por último, la tercera pira, ya en el futuro extraliterario, viene dada por aquella donde se consume la ciudad toda.

Ahora bien, la mención de Eetión, el padre de Andrómaca en los versos en los que la princesa se va desprendiendo de sus adornos, permitiría incluir una cuarta pira en la serie, ubicada esta en el pasado pero con vinculación clara con el presente. En efecto, en el canto VI se nos informa que Aquiles, el actual asesino de su esposo, también mató a Eetión y no lo

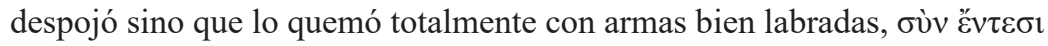
$\delta \alpha \iota \delta \alpha \lambda \dot{\varepsilon}$ oı $\sigma ı v,(V I$, v. 418). En la Tebas asiática se da un ritual funerario pervertido (a continuación levanta un túmulo) en función de la persona que lo llevó a cabo, el asesino del muerto a honrar (otra relación de authéntes para Andrómaca); en el presente troyano también parece procederse a un ritual funerario fuera de norma al suplantarse el cadáver por sus finas y hermosas vestiduras.

Con estas proyecciones al pasado y al futuro que Andrómaca efectúa por intermedio de objetos textiles, vemos también en su caso cómo se le ha conferido a este personaje una capacidad de configurar la trama narrativa. Las referencias textiles aparecen, entonces, como el ámbito más propicio para desarrollar tal capacidad.

A manera de conclusión, podríamos decir que ambas mujeres a través del mundo textil perfilan unos desarrollos narrativos que hace al conjunto de la composición hilando presente, pasado y futuro. Helena plasma el presente de manera literal y extraordinaria pero abre un mundo de connotaciones que conecta con los momentos originarios del conflicto y prefigura los acontecimientos que van a suceder. Andrómaca, por su parte, parece 
ser más ingenua respecto de las circunstancias que la rodean en el presente pero, una vez que toma conciencia del quiebre producido con la muerte de su esposo despliega un abanico de interacciones con lo textil que también proyecta hacia el pasado personal y prefigura el futuro propio de los habitantes de Troya. En un género como la épica donde la guerra es omnipresente y por eso las mujeres cumplen un rol absolutamente secundario sea en carácter de objetos de disputa o de víctimas de la violencia de la guerra vemos entonces a dos personajes femeninos que a través de su interacción diversificada con el mundo textil cumplen un papel en la trama de relevancia estructural.

\section{Referencias bibliográficas}

BARBER, Elizabeth J. W. Weaving the social fabric. In: GILLIS, Carole; NOSCH, Marie-Louise B. (eds.). Ancient textiles. Production, craft and society. Oxford: Oxbow Books, 2007, p. 1-5.

BELFIORE, Elizabeth S. Murder among friends. Violation of philia in Greek tragedy. Oxford: University Press, 2000.

BENDER JØRGENSEN, Lise. The world according to textiles. In: GILLIS, Carole; NOSCH, Marie-Louise B. (eds.). Ancient textiles. Production, craft and society. Oxford: Oxbow Books, 2007, p. 1-5.

BERGREN, Ann. Weaving truth. Essays on language and the female in Greek thought. Washington: Center for Hellenic Studies, 2008.

CANEVARO, Lilah Grace. Women and memory: the Iliad and the Kosovo cycle. In: CASTAGNOLI, Luca; CECCARELLI, Paola (eds.). Greek memories. Theories and Practices. Cambridge: University Press, 2019, p. 53-67.

DE JONG, Irene J. F. Homer. Iliad. Book 22. Cambridge: University Press, 2012.

HUGHES, Lisa. "Dyeing' in Ancient Italy? Evidence for the purpuraii. In: GILLIS, Carole; NOSCH, Marie-Louise B. (eds.). Ancient textiles. Production, craft and society. Oxford: Oxbow Books, 2007, p. 1-5.

IRIARTE, Ana; GONZÁLEZ GONZÁLEZ, Marta. Entre Ares y Afrodita. Violencia del erotismo y erótica de la violencia en la Grecia antigua. Madrid: Abada, 2008.

KENNEDY, George A. Helen's web unraveled. Arethusa, Baltimore, v. 19, n. 1, p. 5-14, 1986. 
KIRK, G. S. The Iliad. A Commentary. Books 1-4. Cambridge: University Press, 2001 [1985]. v. 1.

LEAF, Walter. The Iliad (edited with apparatus criticus, prolegomena, notes, and appendices). Londres: Macmillan, 1900.

LEE, Mireille M. Dress and adornment in Archaic and Classical Greece. In: JAMES, Sharon L.; DILLON, Sheila (eds.). A companion to women in the Ancient world. Oxford: Blackwell Publishing, 2012, p. 179-190.

LIDDELL, Henry George; SCOTT, Robert; JONES, Henry Stuart. Greek-English Lexicon. Oxford: Clarendon Press, 1968.

MALTA, André. Metapoesia e a Helena de Homero. Nuntius Antiquus, Belo Horizonte, v. 12, n. 1, p. 13-25, 2016.

MONRO, David B.; ALLEN, Thomas W. Homeri Opera. Iliadis libros I-XII continens. Oxford: Clarendon Press, 1988 [1902]. t. I.

MONRO, David B.; ALLEN, Thomas W. Homeri Opera. Iliadis libros XIII-XXIV. Oxford: Clarendon Press, 1988 [1902]. t. II.

MUELLER, Melissa. Helen's hands: weaving for kleos in the Odyssey. Helios, Lubbock (Texas), v. 37, n. 1, p. 1-21, 2010.

PANTELIA, Maria C. Spinning and weaving: ideas of domestic order in Homer. The American Journal of Philology, Baltimore, v. 114, n. 4, p. 493-501, 1993.

RICHARDSON, Nicholas. The Iliad: a commentary (Books 21-24). Cambridge: University Press, 2000 [1993]. v. VI.

RODRÍGUEZ ADRADOS, Francisco (dir.). Diccionario griego-español. Madrid: CSIC, 1989. v. I.

RODRÍGUEZ CIDRE, Elsa. Feminizar las póleis: tratamiento diferencial de Troya y Tebas en Eurípides. In: AMES, Cecilia; SAGRISTANI, Marta (Comps.). Estudios Interdisciplinarios de Historia Antigua IV (IV Jornadas Nacionales y III Internacionales de Historia Antigua, Córdoba, 21-24 de mayo de 2012). Córdoba: Universidad Nacional de Córdoba, 2014, p. 167-178. E-Book. ISBN: 978-950-33-1142-4.

RODRÍGUEZ CIDRE, Elsa. Mostrar los pechos: la tragedia euripidea y la problemática del cuerpo en escena. In: RODRÍGUEZ CIDRE, Elsa; BUIS, Emiliano J. (eds.). La pólis sexuada: normas, disturbios y transgresiones del género en la Grecia Antigua. Buenos Aires: Editorial de la FFy L/UBA, 2011, p. 59-83.

ROISMAN, Hanna M. Helen in the "Iliad" "causa belli" and victim of war: from silent weaver to public speaker. The American Journal of Philology, Baltimore, v. 127, n. 1, p. 1-36, 2006. 
SEGAL, Charles. Andromache's anagnorisis: formulaic artistry in Iliad 22.347-476. HSPh, Cambridge/Massachusetts, v. 75, p. 33-57, 1971.

SEYMOUR, Thomas D. Commentary on Homer's Iliad, Books I-III. Boston: Ginn and Company, 1891.

WAGNER-HASEL, Beate. The fabric of gifts: culture and politics of giving and exchange in Archaic Greece. Lincoln: University of Nebraska, 2020 [2000].

\section{Notas}

${ }^{1}$ La edición base es la de Monro \& Allen, 1988 [1902]. Las traducciones nos pertenecen en todos los casos.

${ }^{2}$ Como señala Barber (2007, p. 3), si las mujeres generalmente se ocupan de lo textil, parece razonable que ellas se inclinen a codificar sus esperanzas y temores en esos objetos.

${ }^{3}$ Un ejemplo donde podríamos detenernos está dado por las acepciones del verbo

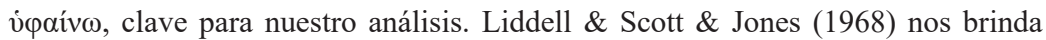
tres acepciones: 1. "tejer", 2. "idear"/“planear" estrategias buenas o malas que son ingeniosamente imaginadas y 3. "crear"/"construir". En esta última considera una segunda posibilidad: "componer"/“escribir" aunque es de destacar que para la tercera acepción los ejemplos ya son de Píndaro o Platón.

${ }^{4}$ En el caso de las Moiras: IV, v. 517; V, v. 83 y v. 613; XII, v. 116; XVI, vv. 433 y ss. y vv. 849 y ss.; XIX, v. 87; XX, v. 128; XXIV, v. 132 y v. 209 (también Odisea III, v. 269 y XI, v. 292). Para las Kéres: I, v. 228 y v. 416; II, v. 302; III, v. 454; VIII, vv. 70 y ss.; IX, vv. 410 y ss.; XI, vv. 330 y ss.; XVIII, vv. 114 y ss. y vv. 535 y ss.; XXII, v. 102 y vv. 209 y ss.; XXIII, vv. 78 y ss.

${ }^{5}$ Para otra lectura, cf. Malta (2016, p. 16).

${ }^{6}$ Para las diferentes tonalidades del color, cf. Leaf, 1900; Wagner-Hasel, 2020 [2000], 175 y 301. Hughes, 2007, 1, señala que Plinio relata en HN 35.26.45 que la concha de murex se utilizaba para hacer un pigmento púrpura que estaba disponible en Grecia (por ejemplo, en Laconia), en el norte de África y en Italia.

${ }^{7}$ Por ejemplo, corte de brazo (V, v. 83), tajo de espada en cuello (XVI, v. 334), tajo de espada en cabeza (XX, v. 476).

${ }^{8}$ Versos similares aparecen para los huesos de Patroclo aunque no está presente la referencia cromática (XXIII, vv. 252-254). 
${ }^{9}$ Para un análisis del tejido de Helena en Odisea, cfr. Mueller (2010).

${ }^{10}$ Para la debatida cuestión del bordado, cf. Wagner-Hasel (2020 [2000], p. 163).

${ }^{11}$ Uno no puede dejar de recordar el momento en el canto VI en el que Héctor, en compañía de su esposa y su hijo, se quita el casco para que Astianacte lo reconozca (VI, vv. 466 y ss.).

${ }^{12}$ Para una feminización de Troya y Tebas en Eurípides, cf. Rodríguez Cidre (2014).

${ }^{13}$ Recordemos que los griegos llaman authéntes al vínculo que denota una suerte de perversión del parentesco, en el sentido de una unión no dada en virtud de la philia, sino a partir del homicidio de un familiar (BELFIORE, 2000, p. 81-85).

${ }^{14}$ El otro velo maternal es el que aparece también en el último canto (XXIV, vv. 93-94) en función de la diosa Tetis. 